\title{
Minimum package for cross-border TB control and care in the WHO European region: a Wolfheze consensus statement
}

\author{
Masoud Dara, Pierpaolo de Colombani, Roumyana Petrova-Benedict, Rosella Centis, \\ Jean-Pierre Zellweger, Andreas Sandgren, Einar Heldal, Giovanni Sotgiu, \\ Niesje Jansen, Rankica Bahtijarevic and Giovanni Battista Migliori on behalf of the \\ members of the Wolfheze Transborder Migration Task Force
}

ABSTRACT: The World Health Organization (WHO) European region estimates that more than 400,000 tuberculosis (TB) cases occur in Europe, a large proportion of them among migrants.

A coordinated public health mechanism to guarantee TB prevention, diagnosis, treatment and care across borders is not in place. A consensus paper describing the minimum package of cross-border TB control and care was prepared by a task force following a literature review, and with input from the national TB control programme managers of the WHO European region and the Wolfheze 2011 conference. A literature review focused on the subject of TB in migrants was carried out, selecting documents published during the 11-yr period 2001-2011.

Several issues were identified in cross-border TB control and care, varying from the limited access to early TB diagnosis, to the lack of continuity of care and information during migration, and the availability of, and access to, health services in the new country.

The recommended minimum package addresses the current shortcomings and intends to improve the situation by covering several areas: political commitment (including the implementation of a legal framework for TB cross-border collaboration), financial mechanisms and adequate health service delivery (prevention, infection control, contact management, diagnosis and treatment, and psychosocial support).

KEYWORDS: Control, Europe, human rights, immigration, multidrug-resistant tuberculosis, tuberculosis

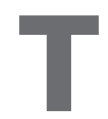

uberculosis (TB), HIV / AIDS and malaria are important clinical and public health issues worldwide. The World Health Organization (WHO) estimates that 8.8 million new TB cases and 1.4 million deaths occurred in 198 countries due to TB in 2010 [1]. Of these numbers, 418,000 patients and 60,000 deaths due to TB are estimated in the WHO European region, a large proportion of them among migrants [2]. Despite the wide difference in $\mathrm{TB}$ notification in the region (from 2.8 to 123 per 100,000 population), TB is considered a public health problem in most countries, particularly among the vulnerable populations (i.e. individuals at higher risk of exposure to discrimination, hostility or economic adversity) frequently located in cities of low incidence countries [3, 4]. The reported treatment success of patients in the WHO European region have been, aberrantly, the lowest among all WHO regions, with $68.7 \%$ and $47.6 \%$ for the 2009 cohorts of new and previously treated patients, respectively. During the same period, default rates were up to $6.4 \%$ and $11.3 \%$ among new and previously treated patients, respectively. Most patients moving from one country to another are lost to follow-up (defaulters, transfers out and unknown) with $11 \%, 17 \%$ and $22 \%$ among new, previously treated and multidrug-resistant (MDR)TB patients, respectively $[1,2]$.
AFFILIATIONS

Author affiliations and a full list of task force members can be found in the Acknowledgements section.

\section{CORRESPONDENCE}

G.B. Migliori

World Health Organization

Collaborating Centre for Tuberculosis and Lung Diseases, Fondazione S. Maugeri

Care and Research Institute

Via Roncaccio 16

21049

Tradate

Italy

E-mail: giovannibattista.migliori@

fsm.it

Received:

March 302012

Accepted after revision:

May 042012

First published online:

May 312012

This article was modified in April 2016 to correct errors in the licence information. 
Several factors have led to an increase of population mobility in the WHO European region, including establishment of the European Union (EU) and free movement within the Newly Independent States, particularly for seasonal labour. The increased population mobility requires an effective and sustainable mechanism to coordinate interventions ensuring quality TB prevention and care, including early diagnosis, uninterrupted treatment and patient support across borders (fig. 1) [6].

Quality diagnosis and treatment of TB are both individual human rights (independent of legal or residential status of the patient) and public health pre-requisites to prevent further development of MDR-TB and extensively drug-resistant (XDR)-TB. Given the alarming increase in prevalence of drug resistance in the $\mathrm{WHO}$ European region, a specific regional effort was conducted [7] to complement the global efforts to eliminating TB by 2050, as targeted by the Stop TB Partnership (table 1) [8].
The rights to health and access to healthcare are defined in article 12 of the 1966 United Nations International Covenant on Economic, Social and Cultural Rights and ratified by most of the countries in the world [9]. For health authorities, there is an internationally agreed ethical obligation to provide universal access to TB and drug-resistant TB care, which should include the use of quality drugs free of charge for all patients through culturally competent and gender sensitive services [10]. These services have to be tailored for those individuals who face increased risk of getting infected with $\mathrm{TB}$ and developing active $\mathrm{TB}$, and for those with higher risk of defaulting treatment and having challenges of accessing and fully utilising services, including refugees, asylum seekers, migrants and mobile populations [11]. For undocumented migrants, the International Union against Tuberculosis and Lung Disease specifically recommends that easy access to $\mathrm{TB}$ diagnosis is ensured and that no deportation takes place until the end of treatment [12]. In some countries, however, denial of entry of

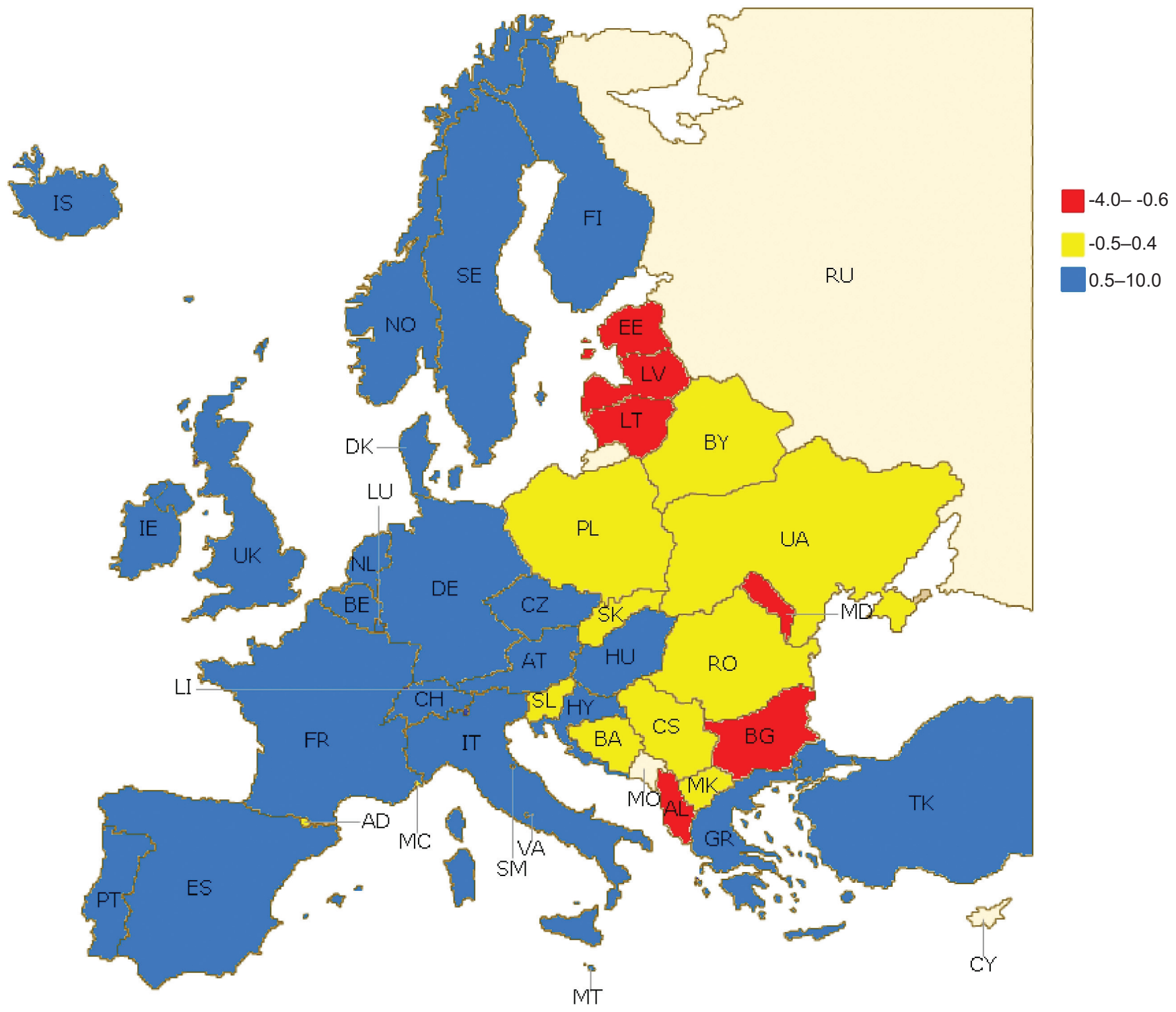

FIGURE 1. Net migration rate in Europe (difference between the number of persons entering and leaving a country during the year per 1,000 persons). Adapted from [5]. 
TABLE 1 Tuberculosis reported new cases by geographic origin in the World Health Organization European region, 2010

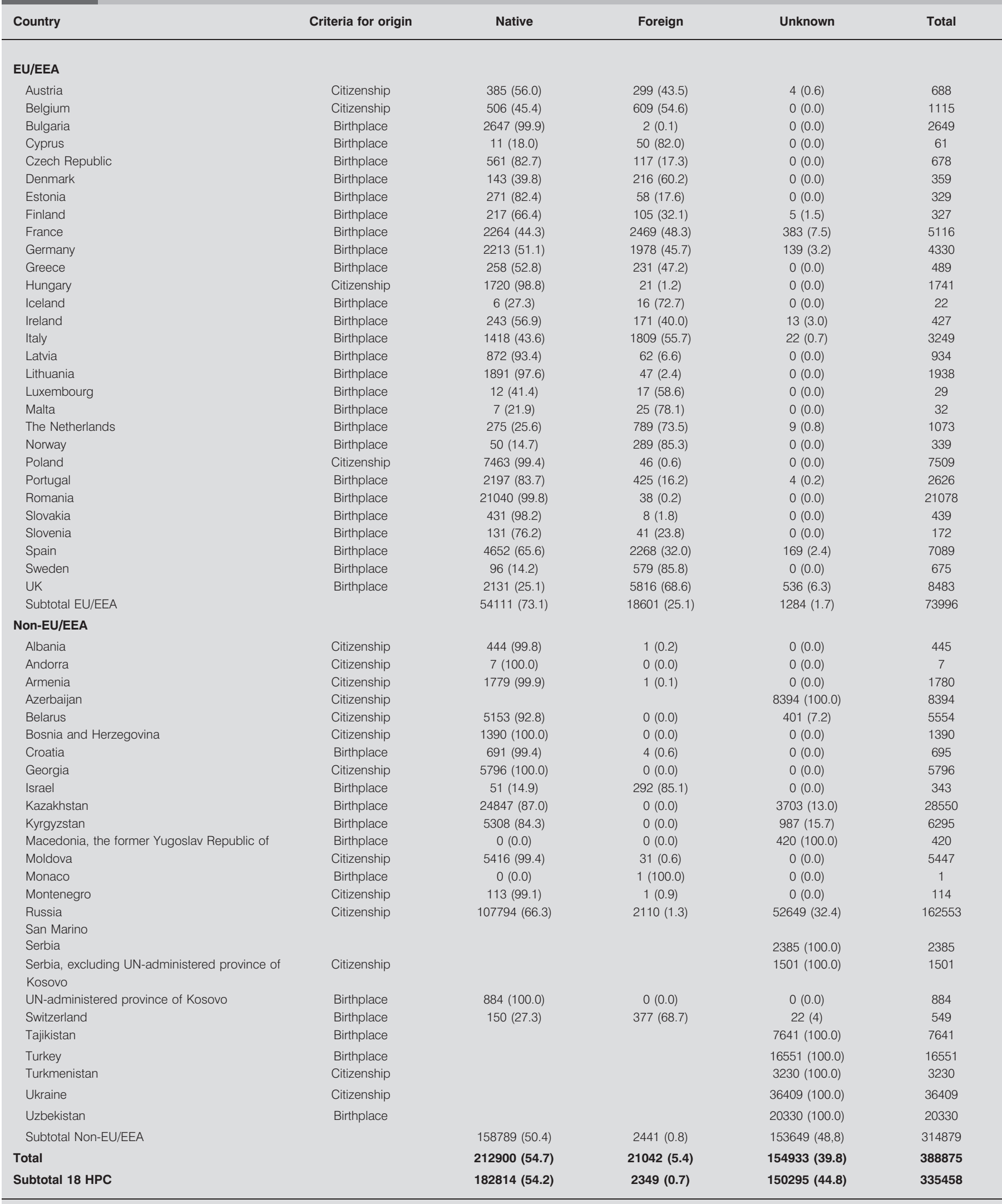

Data are presented as $n$ or $n(\%)$. EU: European Union; EEA: European Economic Area; UN: United Nations; HPC: high priority countries. 
TB suspects is enforced and if vulnerable individuals, such as asylum seekers or undocumented migrants, are diagnosed with $\mathrm{TB}$, they may be extradited without continuity of $\mathrm{TB}$ treatment being ensured [12-15]. For TB patients crossing national borders, there is often lack of continuity of treatment due to lack of patient-centred approaches and/or availability of sound transfer mechanisms [13-15].

Under the Wolfheze's movement initiative, a task force [16] of experts discussed the minimum package of cross-border TB control and care [17]. A literature review was conducted and the concept paper was discussed and finalised with input from the national TB control programme managers of the WHO European region and Wolfheze 2011. This consensus paper defines the minimum package of cross-border TB control and care in the WHO European region.

\section{METHODS}

A review of the evidence relevant for the development of this document was performed. PubMed, EMBASE results and grey literature were evaluated in order to find articles dealing with the topic "TB and migration"; the selected publication period was January 2001 to December 2011. In addition, all the abstracts published over the same period in the International Journal of Tuberculosis and Lung Disease were checked.

Combinations of the following search terms were used: "tuberculosis", "multidrug-resistant tuberculosis", "extensively drug-resistant tuberculosis", "MDR", "XDR", , immigration", "migration", "migrants", "human rights", "asylum seekers", "ethnic minorities" and "Europe". The search was not restricted to publications in English. In addition, bibliographies of retrieved articles were also hand-searched and relevant documents were provided by the national delegates represented in Wolfheze workshops.

Citations were independently screened by three investigators (M. Dara, A. Sandgren and G.B. Migliori) by examining titles and abstracts to identify potentially relevant studies, and differences were resolved by consensus.

The evidence collected was organised in the following sections: key challenges, relevant legal framework, international health regulations and European experiences. On the basis of this evidence, the minimum package for cross-border TB control and care was finally developed by the task force.

\section{DEFINITIONS}

A "migrant" is an individual who changes his/her nation of usual residence [3].

A "long-term migrant" is defined as a subject who moves to a nation other than that of his/her usual residence for $\geqslant 365$ days (the country of destination becomes his/her new country of residence) [3].

A "short-term migrant" is defined as a subject moving to a country other than that of his/her usual residence for a period ranging from $\geqslant 3$ months to $<12$ months, except for holiday, visits to friends and relatives, business, medical assistance or pilgrimage [3].

An "undocumented migrant" is a person who, owing to unauthorised entry or the expiry of his/her visa, lacks legal status in a transit or host country. "Illegal" is not used because it implies a criminal connotation [3].

According to the 1951 Refugee Convention, a "refugee" is someone who, owing to a well-founded fear of being persecuted because of race, religion, nationality, politics or membership of a particular social group, is outside his/her usual country of residence, and is unable to, or unwilling to, avail himself/herself of the protection of that country [3].

An "asylum seeker" is a person seeking security from persecution in a country other than his/her own and awaits a decision on the application for refugee status under relevant international and national instruments. In case of a negative decision, he/she may be expelled unless permission to stay is provided on humanitarian or other related grounds.

A "migrant worker" is a person who is to be engaged, is engaged or has been engaged in a remunerated activity in a state of which he or she is not a national (article 2(1), International Convention on the Protection of the Rights of All Migrant Workers and Members of Their Families, 1990) [3].

"MDR-TB": TB caused by mycobacterial strains showing in vitro resistance to at least isoniazid and rifampicin, the two most potent first-line drugs for TB treatment [1].

"XDR-TB": TB caused by mycobacterial strains showing in vitro resistance to isoniazid and rifampicin plus any fluoroquinolone and at least one of the injectable second-line drugs; amikacin, capreomycin or kanamycin [1].

"Europe" is defined as the WHO European region, composed of 53 member states, if not otherwise specified [17].

"EU" indicates the European Union, composed of 27 member states [18].

"EEA" refers to the European Economic Area.

"Individuals crossing borders": for practical purposes, the current paper refers to all individuals who, for any reason, travel from one country to another for any period of time [3].

"Wolfheze": a series of workshops named after a village in the Netherlands where KNCV Tuberculosis Foundation, WHO and other technical agencies jointly organised a series of workshops, known as the "Wolfheze Workshops", for the National TB Programme (NTP) managers of low TB prevalence countries in western Europe. The aim of the workshops was to redefine TB control in the WHO European region, with emphasis on formulating guidelines and standards based on a consensusbuilding approach. Consensus was attained through extensive consultations among TB control experts, national correspondents and representatives of health ministries. This group was later expanded to all countries of the region.

\section{KEY CHALLENGES OF CROSS-BORDER TB CONTROL AND CARE}

Countries of the WHO European region face an array of challenges in cross-border TB control. These include limited access to early TB diagnosis, a lack of continuity of care for TB patients when they move to another country, and no or little information to the health providers in the countries of transit, destination and return [17-19]. In addition, there is often lack of 
appropriate and/or adequate information for patients as to their rights, availability of health services, coverage entitlements and accessibility of services $[12,18,20]$. In some countries, there is no provision for the coverage of the costs of TB diagnosis and treatment, which mainly rely on individual payment. Accessing healthcare can be a special challenge for migrants [17, 20]. These are further complicated by cultural and language barriers, stigma and fear of deportation.

The fear of discrimination and, furthermore, of deportation because of TB may result in the hiding symptoms and delay in diagnosis, commencement of self-treatment or even a treatment already started to be discontinued, which can eventually lead to development of (multi)drug-resistant TB [12]. Deporting migrants can cause the discontinuation of their treatment [19], even when deported to other EU countries of the Schengen area [note: the Schengen Area currently consists of 26 states (Austria, Belgium, Czech Republic, Denmark, Estonia, Finland, France, Germany, Greece, Hungary, Iceland, Italy, Latvia, Liechtenstein, Lithuania, Luxembourg, Malta, the Netherlands, Norway, Poland, Portugal, Slovakia, Slovenia, Spain, Sweden and Switzerland), all but four of which are members of the EU (Iceland, Norway, Switzerland and Liechtenstein)].

The shortcomings of TB care across borders stem from lack of coordination between the member states of the WHO European region, inadequate legal framework and insufficiencies of health systems to deal with cross-border TB control and care, including accurate and adequate data collection [18-20]. For example, geographic origin of patients is reported in $98.3 \%$ of cases in EU/EEA countries, but in only $51.2 \%$ of cases in non-EU/EEA countries [2].

\section{RELEVANT LEGAL AND POLICY FRAMEWORK FOR CROSS-BORDER TB CONTROL AND CARE}

The legal framework applied in the WHO European region for cross-border TB control and care is quite different among countries. While in some countries free TB diagnosis and treatment is provided to all residents irrespective of their nationality or status (e.g. Norway and Kazakhstan), in others a legal framework allowing free access to health services does not exist, is not fully developed, or is not applied in practice. In some countries, health professionals and social workers are prevented by law from reporting TB cases to police/immigration authorities, while in others health professionals and social workers are required to do so, regardless of their professional oath.

In the EU countries, the European Council Regulation 343 of February 2003, known as "Dublin II Regulation" [21], has established the criteria and mechanisms for determining the country responsible for examining asylum applications by a third-country national. This regulation was issued to limit the "asylum shopping" and to ensure that each asylum applicant's case is processed by one country only. It is usually the country where the application was deposited first that has the responsibility of providing asylum (even if on a temporary basis), including provision of access to healthcare. Consequently, a country diagnosing $\mathrm{TB}$ in an asylum seeker may elect to transfer this patient to the country where the application for asylum was first deposited, even if TB treatment is still ongoing.

More recently, the European Council approved the Directive $2011 / 24$ /EU on patients' rights in cross-border healthcare, as an attempt to regulate cross-border healthcare in the EU's free mobility context by mandating that patients are treated equitably on the basis of their needs rather than on the basis of their member state affiliation [22]. It requires that information is provided to the patients via national contact points for cross-border healthcare, which need to be set up. National health services will need also to have access to a repository of information from European reference networks, where the protection of individual data will be provisioned by the European Council Directive 95/46/EC [23] and the Directive 2002/58/EC [24] concerning the processing and protection of personal data in electronic communications. The Directive, however, is applicable only to insured EU citizens and regularly residing third-country nationals, and remains to be fully implemented.

In March 2011, the European Parliament approved the resolution on "Reducing health inequalities in the EU" calling on member states and the EU institutions for universal, equitable and affordable access to healthcare for all, especially for undocumented migrants, including access to quality legal advice and information about their individual rights [25].

In non-EU countries of the WHO European region, related legal frameworks are rather vague or non-existent [26, 27]. Diverse national legislations consider cross-border TB control and care. Some of them ensure free diagnosis and treatment of TB for all residents irrespective of their nationalities or legal status. Others are much vaguer and some countries do not have any specific framework. Those countries, however, are signatories to commitments to uphold the right to health for all [9] and to the WHO World Health Assembly Resolution 61.17 on "Health of migrants" [28, 29]. In November 2011, the Committee of Ministers of the Council of Europe (47 member states) adopted the recommendations on mobility, migration and the access to healthcare, further outlining and detailing necessary action at national level as well as collaboration between states [29].

\section{INTERNATIONAL HEALTH REGULATIONS}

Since June 15, 2007, the revised International Health Regulations (IHR) have been implemented by all countries worldwide [30]. The full implementation of this legally binding agreement will significantly contribute to global public health security by providing a framework for the coordinated management of events that may constitute a public health emergency of international concern, and by promoting the capacity of all countries to detect, assess, notify and respond to public health threats. Although TB is not listed on the group of diseases that constitute a public health emergency, the network developed for IHR could be used in promoting the continuum of care of TB patients. IHR is generally applicable to trans-national TB transmission; thus, notification of TB to WHO could be considered if the episode raises an important concern to international public health.

Additional details are provided in the online supplementary material.

\section{EUROPEAN EXPERIENCES ON CROSS-BORDER TB CONTROL}

In spite of the information available on $\mathrm{TB}$ cases notified among migrants in Europe (both in terms of absolute numbers and proportions) obtained through country surveillance 
(table 1), and on the net migration rate in Europe (difference between the number of persons entering and leaving a country during the year per 1,000 persons) (fig. 1) not much is known about cross-border TB control.

Although several projects aimed at creating a framework of collaboration on epidemiological issues, in order to improve communicable disease surveillance, communication and training across countries, have been implemented in Europe, academic publications on the topic are scanty and much remains to be achieved in practice. Examples of such work include the EpiSouth project [31] for the Mediterranean and the Balkans and the International Circumpolar Surveillance [32] and the EpiNorth initiative [33]. Other projects undertook a situational analysis at the new EU borders and identified needs for systematic monitoring and provision of adequate healthcare, as well as for cross-sectoral and cross-border collaboration, in view of gaps of continuity of care for asylum seekers and migrants held in places of detention [34].

At the country level, several recent examples are emerging, as follows.

In Norway, undocumented migrants in principle have free access to TB diagnosis. TB suspects may go to the municipal 24-h emergency clinic in the capital, although fear of police may still create a hindrance. Since 2009, several non-governmental organisations (Church City Mission and Norwegian Red Cross) have operated a low-profile, low-threshold health centre for undocumented migrants in the capital city, Oslo. Once suspected of being affected by TB, the patients can apply to the migration authorities for temporary permission to stay in the country. Commonly, this permission is granted, in accordance with the 2009 revised immigration regulations stating that foreigners who are under investigation of (or treatment for) TB should not be forced to leave the country before the suspicion of disease has been discarded, or the treatment has been completed [35]. This regulation formalised the practice established in recent years. Exceptions can be made in special cases, justifiable from a health perspective, if there are possibilities for continuum of care, or other special reasons. Currently, the practice is not to deport TB patients during treatment, including to the so-called "Dublin countries". There are presently no indications that this policy has attracted patients to Norway.

Switzerland has implemented a system of TB screening among asylum seekers and refugees at the border. The system detects some cases of TB every year [36]. A larger group of migrants affected by TB are detected during their stay in the country, while waiting for a legal decision or after a decision has been taken. If a case of TB is detected during this period, asylum seekers are allowed to stay in Switzerland until the completion of TB treatment, whatever the final decision will be (refugee status granted or rejected). However, a migrant belonging to the Dublin Declaration has to leave Switzerland and turn back to the European country where the application for asylum was first deposited. If the delay for transfer back allows, the treatment may be completed in Switzerland. If the delay for transfer back is too short (i.e. diagnosis of TB shortly before the deadline for transfer back), the treatment may have to be completed in another European country. The migration authorities (Swiss
Office for Migrations) offer help and assistance for organising further treatment at an appropriate service in the country of transfer. In contrast to asylum seekers and refugees, undocumented migrants with TB are not allowed to stay in the country and are threatened with rejection and deportation at any time. Furthermore, they usually have no health insurance which can cover the costs for TB treatment, except in some cities. In practice, it is rather easy to postpone rejection, even for undocumented migrants, until the treatment of TB is completed, while the financial burden of the TB treatment is the main problem and has to rely on private or charitable funding.

The Russian Federation is a destination country for thousands of new migrants from many countries of the former Soviet Union, including undocumented labour migrants and refugees. By law and linked to the work and residence permit, they have to be screened for infectious diseases, including TB, at their own expense. TB is a condition which can justify deportation within 15 days of diagnosis. In March 2009, a survey was conducted jointly by the International Organization for Migration (IOM) and WHO among labour migrants in Tajikistan to elucidate key factors influencing access to TB diagnosis and treatment both in their labour destination country (largely the Russian Federation) and at home. The study showed that migrants have increased vulnerability to TB due to the working and living conditions in the destination country and that access to health services is limited due to their legal status or the high cost of health services abroad [37]. The preliminary results of the survey were presented in a round table in Moscow in July 2009 and possible interventions were identified jointly by the Tajikistan and Russian participants.

The Netherlands changed the Migration Act at the end of 2009 [38]. Since then has not been allowed by law to deport migrants to another country while it is suspected that they are affected by TB. This includes also asylum seekers belonging to the Dublin Regulation. In the Migration Act it is also laid down that when migrants (including undocumented migrants, asylum seekers and foreigners with a temporary permit) are diagnosed with TB, they have the right to stay legally in the Netherlands for the whole treatment duration. Unfortunately, the Migration Act does not allow asylum seekers belonging to the Dublin Regulation to stay in the country till the completion of treatment (unless they are still sputum smear positive). However, relevant efforts have been taken to ensure continuation of their treatment in the country of destination. But this is often very hard to do and no good follow-up is possible. In 2008 , five cases on TB treatment were reported to have been transferred outside the Netherlands, but it was not clear whether these transfers were due to the Dublin Regulation and research had to be started to retrieve more information about this patient group.

Further to its broader work in continued advocacy for upholding the right to health for migrants, regardless of status, and for migrant sensitive health systems, the IOM is performing health assessment among migrants, as well as for refugees within the framework of their resettlement to UK, France, Germany, Norway, Sweden, Finland and several other European countries. The health assessment protocols significantly vary by country but most of them do include TB screening. The major health assessment project in relation to 
the European countries is the UK TB Detection Programme in eight high-prevalence countries, where IOM assessed around 482,000 UK visa applicants between October 2005 and December 2010. In several locations, IOM offers treatment to visa applicants diagnosed with TB, as well as, increasingly, health education.

\section{THE MINIMUM PACKAGE FOR CROSS-BORDER TB CONTROL AND CARE}

The minimum package presented here represents the minimum standards agreed upon among the Wolfheze group of experts and the NTP managers to ensure cross-border TB control and care (fig. 2). The recommended minimum package aims to break down the key barriers to diagnosis and treatment, and data exchange for migrants and other cross-border travellers with TB.

\section{Governance}

The countries shall ensure full commitment to cross-border TB control and care. A legal framework for TB cross-border collaboration has to be created in non-EU and EU countries, as well as between EU countries and non-EU countries of the WHO European region, to ensure the right to health and the continuum of TB care for all patients regardless of their legal or residential status. Continuity of care can be improved by implementing a few simple activities as follows.

1) The current list of TB services within each member state of the WHO European region, mentioning one or more "reference centre(s)" per country specifically identified for this task. The treating physician will have a useful instrument to refer their patients in case of need. This list should be ideally kept online (with restricted access) and regularly updated. The responsibility of updating the e-mail addresses in the list would lie with each country.

2) The list of national or sub-national focal persons (updated under care of the WHO Regional Office for Europe), if provided to physicians in a timely manner, will further facilitate coordination and hopefully ensure continuity of care. Consensus was reached to indicate in three working days the maximum time necessary to share information on the patient moving from a country to another.

\section{Finance}

In the interest of patients' and public health, health authorities and providers should have ensured/at their disposal, through government funds and the health insurance organisations,

\begin{tabular}{|c|c|c|c|}
\hline \multirow{10}{*}{ 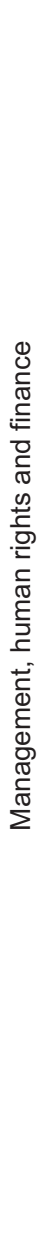 } & \multirow{2}{*}{ Governance } & Legal framework & $\begin{array}{l}\text { Commitment to cross-border TB control and care } \\
\text { Ensure legal basis for cross-border TB control and care within } \\
\text { EU and non-EU, and between EU and non-EU }\end{array}$ \\
\hline & & $\begin{array}{l}\text { Intercountry } \\
\text { correspondence }\end{array}$ & Create and maintain a live list of TB service providers in the region \\
\hline & \multirow[b]{3}{*}{ Service delivery } & Prevention & Diagnosis and treatment of LTBI \\
\hline & & TB infection control & $\begin{array}{l}\text { Administrative measures, } \\
\text { environmental measures } \\
\text { and personal protection }\end{array}$ \\
\hline & & Diagnosis & Early diagnosis including drug-resistant TB \\
\hline & \multirow{3}{*}{$\begin{array}{l}\text { Surveillance and } \\
\text { monitoring }\end{array}$} & \multirow{2}{*}{ Individual patient data } & Effective transfer of patient's record \\
\hline & & & Feedback to the centre sending patients \\
\hline & & Programme performance & $\begin{array}{l}\text { Relevant indicators at country and regional level } \\
\text { measure progress }\end{array}$ \\
\hline & \multirow[b]{2}{*}{ Supportive environment } & Enablers and incentives & $\begin{array}{c}\text { Counselling } \\
\text { Psychosocial support to patients }\end{array}$ \\
\hline & & $\begin{array}{l}\text { Advocacy communication } \\
\text { and social mobilisation }\end{array}$ & $\begin{array}{c}\text { Empower communities for providing migrant-sensitive services } \\
\text { Improve communication with migrant communities } \\
\text { Advocate for full engagement of health authorities } \\
\text { and stakeholders }\end{array}$ \\
\hline
\end{tabular}

FIGURE 2. The minimum package for cross-border tuberculosis (TB) control and care. EU: European Union; LTBI: latent TB infection. 
enough resources to provide diagnosis and treatment of any patient, irrespective of their nationality and legal status, in their country or if moved across the border. Special funds and treaties need to be established within EU or WHO European region member states to ensure reciprocity and cover the costs incurred for treating patients coming from other countries.

A possible common regional fund (regional health insurance) dedicated to the diagnosis and treatment of patients is strongly suggested, especially for undocumented migrants, seasonal workers and international students.

\section{Service delivery}

All services should be culturally competent, respectful of patients' rights and not be at the cost of the patient [10, 13-15, 39]. These services shall be provided without any interruption and designed via participatory consultative approaches, involving patient organisations, cross-border and migrant communities and associations, as well as those representing staff and professionals who are directly involved.

1) Prevention: all people who are crossing a border should have the possibility of accessing preventive measures, including diagnosis and treatment of latent TB infection as applicable, in the transit, host and return country [13-15, 40].

2) TB infection control: administrative and environmental measures and respiratory protection shall be provided in diagnostic and treatment centres as well as during the process of transferring patients to another country [13-15, 41, 42].

3) Contact management: all relevant family members and contacts need to be examined for TB and provided treatment if necessary [43].

4) Diagnosis: all people crossing a border for any reason should be provided free of charge diagnosis of TB infection and disease [12, 19] and drug-resistant TB. The diagnosis services shall be provided in the previously identified "reference centres". The location of these services shall be decided based on each country's health system. Early diagnosis is crucial to improve treatment outcome and break the transmission in the community.

5) Treatment: treatment of TB shall promptly be provided by the first point of contact, irrespective of patients' legal status. Treatment of drug resistant TB and TB/HIV co-infection need to be ensured [44]. Undocumented migrants should not be deported while on treatment $[12,19]$. If they are deported anyway, at least all pulmonary TB patients subject/subjected to holding/detention shall receive treatment until they are smear or culture negative and only after that may an individual be deemed fit for travel.

6) Continuity of care: patients who are diagnosed with TB shall be provided quality treatment [13-15] within the country and beyond the borders. The availability of necessary anti-TB drugs for continuation of treatment should be verified and ensured before the patient is transferred to another country [45]. Most effective for continuity of TB care of undocumented migrants is not deporting them while on treatment. The continuation of treatment shall be ensured between the health services of the country sending and the one receiving the patient.
7) Confidentiality: all health workers are ethically bound and shall respect, and be protected in doing so, their oath in maintaining confidentiality and not reporting TB patients, including undocumented migrants to regulatory authorities for possible deportation. The exception is the patient who rejects treatment and poses danger to public health, and then only after appropriate counselling and psychosocial care; if the patient still refuses to receive treatment, he/she may be reported to the regulatory authorities for involuntary medical isolation. Practising involuntary isolation of patients shall be only exercised in rare cases and if all other attempts to treat the patient fail.

\section{Surveillance and monitoring}

Before the patient is transferred to another country, the complete medical records shall be entrusted to the patient and also shared with the healthcare provider in the recipient country; receipt of information and feedback need to be sent back to the healthcare provider sending the patient. The information should be transmitted in a manner strictly respecting confidentiality and data protection.

Examples of core indicators for monitoring the cross-border TB control and care to be adopted with consistency in all countries include: number of TB patients who were diagnosed as having TB before or after moving to another country, and number of TB patients who crossed the border and successfully completed their treatment.

\section{Supportive environment}

Counselling and advice on treatment adherence shall be an indispensable part of the minimum package for cross-border TB control and care. Psychosocial support and provision of enablers and incentives can play a crucial role for promoting treatment adherence and should be considered a priority intervention.

There is a need to engage civil society organisations, particularly those who can work across the borders and secure treatment of the patients.

Advocacy, communication and social mobilisation should be pursued at national and international levels, and in line with recommendations for provision of migrant sensitive services, to make this information known to both health providers and migrant communities and their leaders.

The progress and performance of mechanisms of collaboration between countries need to be carefully monitored.

\section{CONCLUSIONS}

Intensified actions are needed to address the current gaps in providing TB and drug-resistant TB control and care across borders. A legal framework for TB cross-border collaboration has to be created within the EU, in non-EU countries and between EU and non-EU countries of the WHO European region, in order to ensure the right to health and the continuum of TB care for all patients regardless of their legal or residential status.

In EU countries, an amendment to the Dublin II Regulation on asylum applications is recommended, in order to foster and safeguard the continuity of TB care for asylum seekers. Continuum of TB care between countries should be done 
through a shared updated list of TB services and national focal points for effective and timely communication regarding transferred TB patients.

A minimum package for cross-border TB control and care has been developed by a Wolfheze task force, including known experts and the NTP managers of the WHO European region. National health authorities are called to adopt it. For its successful implementation, a supportive environment is needed and represented by effective patient support and cross-border health insurance schemes and funds, engagement of civil society organisations, advocacy, communication and social mobilisation, and cross-border monitoring mechanisms.

\section{STATEMENT OF INTEREST}

None declared.

\section{ACKNOWLEDGEMENTS}

Author affiliations are as follows. Masoud Dara: World Health Organization, Regional Office for Europe, Copenhagen, Denmark, and KNCV Tuberculosis Foundation, The Hague, The Netherlands; Pierpaolo de Colombani: World Health Organization, Regional Office for Europe, Copenhagen, Denmark; Roumyana Petrova-Benedict: International Organization for Migration, Migration Health Division (MHD), Regional Office, Brussels, Belgium; Rosella Centis and Giovanni Battista Migliori: World Health Organization Collaborating Centre for Tuberculosis and Lung Diseases, Fondazione S. Maugeri, Care and Research Institute, Tradate, Italy; Jean-Pierre Zellweger: Swiss Lung Association, Bern, Switzerland; Andreas Sandgren: European Centre for Disease Prevention and Control (ECDC), Stockholm, Sweden; Einar Heldal: International Union Against Tuberculosis and Lung Disease, Paris, France; Giovanni Sotgiu: Epidemiology and Medical Statistics Unit, Dept of Biomedical Sciences, University of Sassari, Sassari, Italy; Niesje Jansen: KNCV Tuberculosis Foundation, The Hague, The Netherlands; Rankica Bahtijarevic: United Nation Development Programme, Sarajevo, Bosnia and Herzegovina.

The Members of the Wolfheze Transborder Migration Task Force are as follows: Margarita Balasanyan, Head of NTP Central Office, Armenia; Roumyana Benedict, Senior Regional Migration Health Advisor, IOM, Belgium; Victor Botnaru, Director, Pneumology Institute, Moldova; Masoud Dara, Coordinator Wolfheze and Senior TB Consultant, Unit International, KNCV Tuberculosis Foundation, The Netherlands; Pierpaolo de Colombani, Medical Officer, Tuberculosis Control, WHO Regional Office for Europe, Denmark; Gerard de Vries, Head Unit National, KNCV Tuberculosis Foundation, The Netherlands; Svetlana Doltu, Dept of Penitentiary Institutions, Ministry of Justice, Moldova; Connie Erkens, Senior TB Consultant, Unit National, KNCV Tuberculosis Foundation, The Netherlands; Medea Gegia, International Research Programme Coordinator National Centre for Tuberculosis and Lung Diseases, Georgia; Ülgen Güllü, Surveillance Manager, TB Control Department, Ministry of Health, Turkey; Henadz Hurevich, NTP Manager Belarus, Director, Republican Scientific and Practical Center for Pulmonology and TB, Belarus; Niesje Jansen, Senior Nurse Consultant, KNCV Tuberculosis Foundation, The Netherlands; Iagor Kalandadze, NTP Manager Georgia, Executive Director, National Centre for Tuberculosis and Lung Diseases, Georgia; Kai Kliiman, Head of National Tuberculosis Programme, NTP Manager Estonia, Estonia; Davide Manissero, Università degli Studi dell'Insubria, Varese; Vladimir Milanov, NTP Manager Bulgaria, Chief Expert, Ministry of Health, Bulgaria; Nikoloz Nasidze, MSCI, Tbilisi, Georgia; Dmitry Pashkevich, Acting Coordinator, TB Control Programme, WHO Regional Office in the Russian Federation, Russian Federation; Karin Rønning, NTP Manager Norway, Norway; Dmitri Sain, NTP Manager, Moldova; Maruschka Šebek, Senior Consultant Nurse, KNCV Tuberculosis Foundation, The Netherlands; Ivan Solovic, NTP Manager
Slovakia, Chief of TB Department, Slovakia; Dilrabo Ulmasova, NTP Manager Uzbekistan, Director, Republican DOTS Centre, Uzbekistan; and Jaap Veen, Senior Tuberculosis Control Adviser, The Netherlands.

The authors also would like to give thanks and gratitude to all members of the Wolfheze Transborder Migration Task Force (www. euro.who.int/_data/assets/pdf_file/0005/124466/E94368.pdf).

\section{REFERENCES}

1 World Health Organization. Global Tuberculosis Control: WHO Report 2011. World Health Organization Document 2011, Publication No. WHO/HTM/TB/2011.16. Geneva, WHO Press, 2011.

2 European Centre for Disease Prevention and Control/World Health Organization Regional Office for Europe. Tuberculosis Surveillance in Europe 2009. Stockholm, European Centre for Disease Prevention and Control, 2011.

3 International Migration Law N ${ }^{\circ} 25$. Glossary on Migration. 2nd Edn. Geneva, International Organization for Migration, 2011.

4 Kruijshaar ME, Abubakar I, Dedicoat M, et al. Evidence for a national problem: continued rise in tuberculosis case numbers in urban areas outside London. Thorax 2012; 67: 275-277.

5 Index Mundi. Net Migration Rate - Europe. www.indexmundi. $\mathrm{com} / \mathrm{map} / \mathrm{e}=27 \& \mathrm{r}=\mathrm{eu} \& \mathrm{l}=$ en Date last updated: January 1, 2011.

6 Broekmans JF, Migliori GB, Rieder HL, et al. European framework for tuberculosis control and elimination in countries with a low incidence. Recommendations of the World Health Organization (WHO), International Union Against Tuberculosis and Lung Disease (IUATLD) and Royal Netherlands Tuberculosis Association (KNCV) Working Group. Eur Respir J 2002; 19: 765-775.

7 Dara M, Kluge H. Roadmap to Prevent and Combat Drug-resistant Tuberculosis. Copenhagen, World Health Organization, Regional Office for Europe, 2011. Available from www.euro.who.int/_data/ assets/pdf_file/0014/152015/e95786.pdf Date last accessed: March 26, 2012

8 The Stop TB Strategy. Building On and Enhancing DOTS to Meet the TB-related Millennium Development Goals. Geneva, World Health Organization, 2006. Available from http://whqlibdoc.who. int/hq/2006/WHO_HTM_STB_2006.368_eng.pdf Date last accessed: March 26, 2012.

9 International Covenant on Economic, Social and Cultural Rights. United Nations, 1966. www2.ohchr.org/english/law/cescr.htm Date last accessed: March 26, 2012.

10 Better Health for All in Europe: Developing a Migrant Sensitive Health Workforce. Eurohealth 2010; volume 16 (number 1). London, LSE Health, 2010. Available from www.euro.who.int/_data/ assets/pdf_file/0013/122710/Eurohealth_Vol-16-No-1.pdf Date last accessed: March 26, 2012.

11 World Health Organization. Guidance on Ethics of Tuberculosis Prevention, Care and Control. World Health Organization Document 2011, Publication No (WHO/HTM/TB/2010.6). Geneva, WHO Press, 2011.

12 International Union against Tuberculosis and Lung Disease. Recommendations to Ensure the Diagnosis and Treatment of Tuberculosis in Undocumented Migrants, 2008. Paris, International Union against Tuberculosis and Lung Disease, 2008. Available from www.theunion.org/images/stories/resources/RESS_Undocument ed-migrants-Statement_2008.pdf Date last accessed: March 26, 2012.

13 Migliori GB, Sotgiu G, Blasi F, et al. Towards the development of EU/EEA Standards for Tuberculosis Care (ESTC). Eur Respir J 2011; 38: 493-495.

14 Migliori GB, Zellweger JP, Abubakar I, et al. European Union Standards for Tuberculosis Care. Eur Respir J 2012; 39: 807-819.

15 Migliori GB, Sotgiu G, D'Ambrosio L, et al. TB and MDR/XDR-TB in the EU and EEA countries: managed or mismanaged? Eur Respir J 2012; 39: 619-625. 
16 Dara M. Wolfheze 2010. 20 Year Jubilee: Bridging the Gaps, Where Do We Stand After 20 Years? 9th National TB Programme Managers' Meeting of WHO European Region/14th Wolfheze Workshops. Copenhagen, World Health Organization, Regional Office for Europe, 2010. Available from: www.euro.who.int/ _data/assets/pdf_file/0005/124466/E94368.pdf.

17 Veen J, Migliori GB, Raviglione M, et al. Harmonisation of TB control in the WHO European region: the history of the Wolfheze workshops. Eur Respir J 2011; 37: 950-959.

18 Migrants in an Irregular Situation: Access to Healthcare in 10 European Union Member States. Vienna, European Union Agency for Fundamental Right, 2011.

19 Heldal E, Kuyvenhoven V, Wares F, et al. Diagnosis and treatment of tuberculosis in undocumented migrants in low- and intermediate incidence countries. Int J Tuberc Lung Dis 2008; 12: 878-888.

20 Cuadra CB, Cattacin S. Policies on Health Care for Undocumented Migrants in the EU27 and Switzerland: Towards a Comparative Framework. Summary Report. 2nd Edn. http:/ / files.nowhereland. info/757.pdf Date last accessed: March 26, 2012. Last updated: January 2011.

21 The Council of the European Union regulation (EC) No 343/2003. Establishing the criteria and mechanisms for determining the Member State responsible for examining an asylum application lodged in one of the Member States by a third-country national. Brussels, European Union, Council of the European Union, 2003.

22 Directive 2011/24/EU of the European Parliament and of the Council of 9 March 2011. On the application of patients' rights in cross border healthcare. Brussels, European Parliament and Council of the European Union, 2011.

23 Directive 95/46/EC of the European Parliament and of the Council of 24 October 1995. On the protection of individuals with regard to the processing of personal data and on the free movement of such data. Brussels, European Parliament and Council of the European Union, 1995.

24 Directive 2002/58/EC of the European Parliament and of the Council of 12 July 2002. Concerning the progressing of personal data and the protection of privacy in the electronic communications sector (Directive on privacy and electronic communications). Brussels, European Parliament and Council of the European Union, 2002.

25 European Parliament resolution of 8 March 2011. On reducing health inequalities in the EU. www.europarl.europa.eu/sides/ getDoc.do?pubRef=-//EP / /TEXT+TA+P7-TA-2011-0081+0+DOC+ XML+V0//EN Date last accessed: March 26, 2012.

26 International Migration Law $\mathrm{N}^{\circ} 12$. Migration and the Right to Health: A Review of European Community Law and Council of Europe Instruments. Geneva, International Organization for Migration, 2007.

27 International Migration Law $\mathrm{N}^{\circ} 19$. Migration and the Right to Health: A Review of International Law. Geneva, International Organization for Migration, 2009.

28 Health of Migrants. Resolution 61.17 of the 61st World Health Assembly. Geneva, World Health Organization, 2008.

29 Recommendation CM/Rec(2011)13 of the Committee of Ministers to member states on mobility, migration and access to health care. Adopted by the Committee of Ministers on 16 November 2011 at the 1126th meeting of the Ministers' Deputies. http:/ / wcd.coe.int/ ViewDoc.jsp?id=1872157 Date last accessed: March 26, 2012.
30 World Health Organization International Health Regulations. 2nd Edn. Geneva, World Health Organization, 2008.

31 EpiSouth Network for the Control of Public Health Threats in the Mediterranean Region and South East Europe. www.episouthnetwork.org Date last accessed: March 26, 2012.

32 Arctic Infectious Disease Working Groups. www.arcticinfdis.com Date last accessed: March 26, 2012.

33 EpiNorth Co-operation Project for Communicable Disease Control in Northern Europe. www.epinorth.org Date last accessed: March 26, 2012.

34 Samuilova M, Hollings J, Petrova-Benedict R. Increasing Public Health Safety Alongside the New Eastern European Border: An Overview of Findings from the Situational Analysis, 2010. Brussels, International Organization for Migration, 2010.

35 Government of Norway. Regulations of 15 October 2009 on the entry of foreign nationals into the Kingdom of Norway and their stay in the realm (immigrations regulations). www.regjeringen. no/upload/JD/Vedlegg/Forskrifter/Immigration_Regulation.pdf Date last accessed: March 26, 2012.

36 Schneeberger Geisler S, Helbling P, Zellweger JP, et al. Screening for tuberculosis in asylum seekers: comparison of chest radiography with an interview-based system. Int J Tuberc Lung Dis 2010; 14: $1388-1394$.

37 Gilpin C, de Colombani P, Hasanova S, et al. Exploring TB-related knowledge, attitude, behaviour and practice among migrant workers in Tajikistan. Tuberc Res Treat 2011; 2011: 548617.

38 State Secretary of Justice. Besluit van de Staatssecretaris van Justitie van 11 september 2009, nr. 2009/20, houdende wijziging van de Vreemdelingencirculaire 2000 [Decision of the State Secretary of Justice of 11 September 2009, $N^{\circ}$ 2009/20, changing the procedures with foreigners as per related decree of 2000]. State Regulation $N^{\circ} 14307$ of 24 September 2009. http://zoek.officielebekendmakingen.nl/stcrt-2009-14307.html Date last accessed: March 26, 2012.

39 World Health Organization. Health and Migrants: the Way Forward. Report of a Global Consultation, Madrid, Spain, 3-5 March 2010. Geneva, World Health Organization, 2010. Available from www.who.int/hac/events/consultation_report_health_migrants_ colour_web.pdf Date last accessed: March 26, 2012.

40 Leung CC, Rieder HL, Lange C, et al. Treatment of latent infection with Mycobacterium tuberculosis: update 2010. Eur Respir J 2011; 37: 690-711.

41 World Health Organization. WHO Policy on Infection Control in Health-care Facilities, Congregate Settings and Households. World Health Organization, Document 2009. Publication No WHO/HTM/TB/2009.419. Geneva, WHO Press, 2009.

42 Sotgiu G, D'Ambrosio L, Centis R, et al. TB and M/XDR-TB infection control in European TB reference centres: the Achilles' heel? Eur Respir J 2011; 38: 1221-1223.

43 Erkens CG, Kamphorst M, Abubakar I, et al. Tuberculosis contact investigation in low prevalence countries: a European consensus. Eur Respir J 2010; 36: 925-949.

44 Pontali E, Pasticci MB, Matteelli A, et al. Tuberculosis and HIV coinfection: do we have a surveillance system in Europe? Eur Respir J 2011; 38: 1258-1260.

45 Sotgiu G, D'Ambrosio L, Centis R, et al. Availability of antituberculosis drugs in Europe. Eur Respir J 2012; 40: 500-503. 